\title{
Cortical stimulation in pharmacoresistant focal epilepsies
}

Jens Ellrich ${ }^{1,2}$ (1)

\begin{abstract}
Pharmacoresistance and adverse drug events designate a considerable group of patients with focal epilepsies that require alternative treatments such as neurosurgical intervention and neurostimulation. Electrical or magnetic stimulations of cortical brain areas for the treatment of pharmacoresistant focal epilepsies emerged from preclinical studies and experience through intraoperative neurophysiological monitoring in patients. Direct neurostimulation of seizure onset zones in neocortical brain areas may specifically affect neuronal networks involved in epileptiform activity without remarkable adverse influence on physiological cortical processing in immediate vicinity.

Noninvasive low-frequency transcranial magnetic stimulation and cathodal transcranial direct current stimulation are suggested to be anticonvulsant; however, potential effects are ephemeral and require effect maintenance by ongoing stimulation. Invasive responsive neurostimulation, chronic subthreshold cortical stimulation, and epicranial cortical stimulation cover a broad range of different emerging technologies with intracranial and epicranial approaches that still have limited market access partly due to ongoing clinical development. Despite significant differences, the present bioelectronic technologies share common mode of actions with acute seizure termination by high-frequency stimulation and long-term depression induced by low-frequency magnetic or electrical stimulation or transcranial direct current stimulation.

Keywords: Adherence, Anticonvulsant, Chronic subthreshold cortical stimulation, Epicranial cortical stimulation, Long-term depression, Neuromodulation, Responsive neurostimulation, Seizure, Transcranial direct current stimulation, Transcranial magnetic stimulation
\end{abstract}

\section{Background}

Epilepsies are characterized by unpredictable seizures and affect more than 70 million people worldwide (Beghi 2020; Ngugi et al. 2010). Focal seizures are the predominant seizure type in children and adults with a proportion of about 68\% (Forsgren et al. 1996). Seizures are primarily treated by anticonvulsant drugs (ACD) that typically strengthen inhibition and attenuate excitation of synaptic processing via pre- and postsynaptic mechanisms (Loscher and Schmidt 2012). Nearly two dozen ACDs with different mechanisms of action have been introduced over the past three decades with the aim of providing a better efficacy or safety profile than previous

Correspondence: jens.ellrich@fau.de

${ }^{1}$ Medical Faculty, University of Erlangen-Nuremberg, Erlangen, Germany

${ }^{2}$ Precisis AG, Heidelberg, Germany drugs (Chen et al. 2020). Although these recent drugs have advantages in terms of drug-drug interactions and teratogenicity, still a third of epilepsy patients suffer from recurrent seizures (Janmohamed et al. 2020). This pharmacoresistance is defined as failure of adequate trials of two tolerated, appropriately chosen, and used ACD schedules to achieve sustained seizure freedom (Janmohamed et al. 2020; Kwan et al. 2010; Tang et al. 2017). This definition includes and emphasizes that drug treatments are tolerated and used, indicating the impact of adverse events and adherence. A recent meta-analysis assessed the efficacy and tolerability of ACD monotherapies in randomized, double-blinded, parallel group studies in adults with newly diagnosed focal epilepsies (Lattanzi et al. 2019). Whereas $58 \%$ of patients achieved seizure freedom, more than $73 \%$ complained about treatment-emergent adverse events (TEAE). ACD treatment was discontinued in

(c) The Author(s). 2020 Open Access This article is licensed under a Creative Commons Attribution 4.0 International License, which permits use, sharing, adaptation, distribution and reproduction in any medium or format, as long as you give appropriate credit to the original author(s) and the source, provide a link to the Creative Commons licence, and indicate if changes were made. The images or other third party material in this article are included in the article's Creative Commons licence, unless indicated otherwise in a credit line to the material. If material is not included in the article's Creative Commons licence and your intended use is not permitted by statutory regulation or exceeds the permitted use, you will need to obtain permission directly from the copyright holder. To view a copy of this licence, visit http://creativecommons.org/licenses/by/4.0/. 
13\% due to TEAEs (Baulac et al. 2012; Baulac et al. 2017; Brodie et al. 2007; Trinka et al. 2018). ACD treatment can have a significant impact on quality of life and concomitant TEAEs may be more important determinants of quality of life than seizures themselves (Hamer et al. 2015; Luoni et al. 2011). Lack of benefit, TEAEs, and complicated drug regimens are among the most important factors associated with medication non-adherence in epilepsies (Malek et al. 2017). More than $40 \%$ of epilepsy patients are nonadherent with an associated increased mortality risk. Thus, a third of epilepsy patients suffer from ongoing seizures and even more from TEAEs (Billakota et al. 2020).

Pharmacoresistance and TEAEs designate a considerable group of patients with focal epilepsies that requires alternative treatments such as neurosurgical intervention and neurostimulation. Whereas neurosurgical resection can only be applied to non-eloquent brain areas in a minority of patients (Engel Jr. 2018), neurostimulation technologies such as vagus nerve stimulation (VNS) and deep brain stimulation (DBS) affect the cranial vagus nerve or the anterior thalamus, respectively. Both areas are rather remote from the seizure onset zone (SOZ) in focal epilepsies and, therefore, these neurostimulations are accompanied by systemic and unspecific side effects, as well as adverse events (Gonzalez et al. 2019; Salanova et al. 2015). Most frequent adverse events caused by active VNS cover hoarseness, cough, paresthesia, pain, dyspnea, and headache with incidences of up to $62 \%$ (Gonzalez et al. 2019). The clinical importance of asystole, severe bradycardia, and sleep apnea is still under discussion. The most frequent device-related adverse events with active DBS include pain, paresthesia, discomfort, sensory disturbance, memory impairment, and dizziness (Salanova et al. 2015). Depression events were reported in $37 \%$, memory impairment in $27 \%$. Thus, VNS and DBS, have rather different adverse events that are potentially related to the sites of stimulation. With RNS, depression and memory impairment are reported in 25 and 12.5\%, respectively (Nair et al. 2020). These prevalences with RNS tend to be lower than with DBS. However, RNS involves in 69\% of all implantations DBS leads and is performed in only $31 \%$ of patients exclusively by cortical strips localized over the SOZ (FDA 2013). This comparison may indicate that pure neurostimulation of the SOZ may have less systemic and unspecific side effects than remote stimulation by VNS and DBS.

Direct neurostimulation of SOZ in neocortical brain areas may specifically affect neuronal networks involved in epileptiform activity without remarkable adverse influence on physiological cortical processing in immediate vicinity. Penfield and Jasper first applied focal electrical stimulation to humans in order to terminate spontaneous seizures detected by electrocorticography at the time of resective surgery (Penfield and Jasper 1954). Especially in the last decade various neurotechnologies emerged from preclinical and clinical pioneer work aiming at individualized cortical stimulation therapies in pharmacoresistant focal epilepsies (Table 1).

\section{Noninvasive cortical stimulation \\ Transcranial magnetic stimulation (TMS)}

Two recent meta-analyses focused on the clinical efficacy of TMS in pharmacoresistant epilepsies (Lefaucheur et al. 2020; Mishra et al. 2020).

Mishra et al. included seven randomized controlled trials (RCT) that compared repetitive TMS with sham or placebo controls (Mishra et al. 2020). Statistical analyses demonstrated a significant reduction of seizure frequency and interictal epileptiform discharges with active low-frequency TMS ( 0.5 to $1 \mathrm{~Hz}$ ) as compared to control groups. After TMS treatment, anticonvulsant efficacy faded and was unverifiable within weeks suggesting that TMS exerts only a short-term effect.

Lefaucheur et al. identified only one additional shamcontrolled trial in epilepsies that applied repetitive lowfrequency TMS $(0.5 \mathrm{~Hz})$ in the period from 2014 to 2018 as compared to the meta-analysis done in 2014 by the same group (Lefaucheur et al. 2020). The primary level of recommendation $C$, i.e. possible anticonvulsant efficacy, for low-frequency repetitive TMS in epilepsies from 2014 did not change in 2018. However, confounding factors such as differences in paradigms of TMS interventions, types and clinical profiles of epilepsies, and the number of ACDs taken by patients should be considered.

All meta-analyses emphasized the largest clinical trial that involved 60 patients with pharmacoresistant focal epilepsies in order to verify the potential therapeutic value of low-frequency TMS $(0.5 \mathrm{~Hz})$ on a localized epileptic focus (Sun et al. 2012). The randomized, single-blind, controlled parallel group study allocated 60 patients to two groups with different TMS intensities applying $20 \%$ or $90 \%$ of resting motor threshold. Seizure frequency and interictal EEG epileptic discharges were compared between the baseline and follow-up periods of up to 8 weeks after TMS. Seizures and interictal epileptiform discharges significantly decreased following 2weeks high intensity TMS treatment as compared with the baseline level. For the patients, who received low intensity TMS, seizures and spikes in the follow-up period did not show any differences when compared with the baseline data. These results resemble data from a previous RCT in which TMS was applied to the individual epileptic focus in 21 patients, as well (Fregni et al. 2006).

Overall, the most recent meta-analysis suggested a significant beneficial effect of TMS on pharmacoresistant epilepsies reducing both the seizure frequency and 
Table 1 Bioelectronic technologies for cortical stimulation in focal epilepsies

\begin{tabular}{|c|c|c|c|c|c|}
\hline Technology & $\begin{array}{l}\text { TMS } \\
\text { Transcranial Magnetic } \\
\text { Stimulation }\end{array}$ & $\begin{array}{l}\text { tDCS } \\
\text { transcranial Direct Current } \\
\text { Stimulation }\end{array}$ & $\begin{array}{l}\text { RNS } \\
\text { Responsive } \\
\text { NeuroStimulation }\end{array}$ & $\begin{array}{l}\text { CSCS } \\
\text { Chronic Subthreshold } \\
\text { Cortical Stimulation }\end{array}$ & $\begin{array}{l}\text { ECS } \\
\text { Epicranial Cortical } \\
\text { Stimulation }\end{array}$ \\
\hline Invasiveness & Noninvasive & Noninvasive & $\begin{array}{l}\text { Invasive, } \\
\text { Intracranial }\end{array}$ & $\begin{array}{l}\text { Invasive, } \\
\text { Intracranial }\end{array}$ & $\begin{array}{l}\text { Invasive, } \\
\text { Extracranial }\end{array}$ \\
\hline Placement of electrode/coil & Cutaneous & Cutaneous & Subdural & Subdural & Epicranial, Subgalea \\
\hline Stimulation frequency & $0.5-1 \mathrm{~Hz}$ & Direct current & $100-200 \mathrm{~Hz}$ & $2 \mathrm{~Hz}$ & $100 \mathrm{~Hz}, 8 \mathrm{~Hz}$ \\
\hline Mode of actions & LTD & $\begin{array}{l}\text { Hyperpolarization, } \\
\text { LTD }\end{array}$ & Seizure termination & LTD & $\begin{array}{l}\text { Seizure termination, } \\
\text { LTD }\end{array}$ \\
\hline Clinical trials & $\begin{array}{l}\text { Lefaucheur et al. 2020; } \\
\text { Mishra et al. } 2020\end{array}$ & $\begin{array}{l}\text { Lefaucheur et al. 2017; } \\
\text { VanHaerents et al. 2020; } \\
\text { Yang et al. } 2020\end{array}$ & $\begin{array}{l}\text { Morrell and Group } \\
\text { RNSSiES } 2011\end{array}$ & Lundstrom et al. 2019 & $\begin{array}{l}\text { EASEE-\| } \\
\text { PIMIDES-I n.d. }\end{array}$ \\
\hline
\end{tabular}

interictal epileptiform discharges. However, potential anticonvulsant effects seem to be ephemeral and may require effect maintenance by ongoing repetitive TMS.

\section{Transcranial direct current stimulation (tDCS)}

A meta-analysis from 2017 identified 65 papers, including only 10 original clinical studies with 147 patients (Lefaucheur et al. 2017). Besides some case reports, 5 sham-controlled studies with crossover or parallel-arm design including 12 to 37 patients were addressed. No recommendation for cathodal tDCS of the epileptic focus or anodal tDCS of the left dorsolateral prefrontal cortex was given. A recent literature review concluded that study results of cathodal tDCS for refractory epilepsy were promising and suggested that cathodal tDCS may potentially decrease seizures in pharmacoresistant epilepsy patients (VanHaerents et al. 2020).

A very recent $\mathrm{RCT}$ aimed at the anticonvulsant effect of tDCS especially in patients with pharmacoresistant focal epilepsies (Yang et al. 2020). The multicenter clinical trial applied different tDCS paradigms to three groups of patients. Patients in group 2 received $20 \mathrm{~min}$ tDCS per day. Patients in the sham group (group 1) received no real stimulation but went through the same stimulation procedure as those in group 2, being attached with two electrodes for $20 \mathrm{~min}$. For group 3, patients received a total of $40 \mathrm{~min}$ stimulation per day, which was equally separated by a $20 \mathrm{~min}$ interval. The primary outcome measurement was seizure frequency. The study consisted of 28 days baseline, 14 days treatment, and 56 days follow-up. The cathode was placed over the epileptogenic focus, and the current intensity was $2 \mathrm{~mA}$. Seventy patients were included for the final analysis. There was a significant reduction in seizure frequency for both active tDCS groups compared with the sham group. Patients in group 2 showed a significantly greater reduction as compared to the sham group that lasted for 4 weeks. Patients in group 3 showed a significantly greater reduction as compared with the sham group that lasted for 5 weeks. Seizure frequency reduction in group 3 was significantly larger than in group 2. The authors concluded, that tDCS on 14 consecutive days significantly decreased seizure frequency in patients with pharmacoresistant focal epilepsies, with two daily $20 \mathrm{~min}$ stimulations being superior to a $20 \mathrm{~min}$ daily stimulation protocol (Yang et al. 2020).

In contrast to typical tDCS where sustained direct current stimulation is administered for at least $20 \mathrm{~min}$, a slow-pulsed transcranial electrical stimulation protocol applied short cathodal direct current pulses of $100 \mathrm{~ms}$ duration with a frequency of $0.5 \mathrm{~Hz}$ to patients with pharmacoresistant focal epilepsies (Holmes et al. 2019). In all 7 subjects accurate targeting of the cortical focus of epileptic spikes was achieved by the combination of a high-resolution head conductivity model and a 256channel dense EEG system. Interictal spikes were localized, and transcranial electrical stimulation targeted the cortical source of each subject's principal spike population. Baseline EEG recording was followed by three 17 min trains of 500 cathodal pulses each, with trains separated by a 10 min rest interval. Continuous EEG recording for $3 \mathrm{~h}$ followed each of the five daily stimulation sessions and allowed for the assessment of the posttreatment spike rate. Targeted spikes were suppressed in five subjects, and nontargeted spikes were suppressed in four subjects. Epileptiform activity did not worsen.

\section{Invasive cortical stimulation \\ Responsive neurostimulation (RNS)}

The implantable components of the RNS device include a cranially seated internal pulse generator connected to depth and/or cortical strip leads which are surgically placed at the seizure foci (Skarpaas et al. 2019). The neurostimulator continuously senses and monitors electrocorticographic activity at the seizure focus and provides responsive electrical stimulation when abnormal patterns are detected. Stimulation consists of currentcontrolled, charge-balanced biphasic pulses with the stimulation frequency being between 1 and $333 \mathrm{~Hz}$, current between 0.5 and $12 \mathrm{~mA}$, pulse width from 40 to 
$1000 \mu \mathrm{s}$, and a burst duration from 10 to $5000 \mathrm{~ms}$. The most common stimulation settings in the clinical trials were $100-200 \mathrm{~Hz}$ stimulation frequency, $1.5-3 \mathrm{~mA}$ current, $160 \mu$ s pulse width, and $100-200 \mathrm{~ms}$ burst duration (Heck et al. 2014; Skarpaas et al. 2019). Usually, patients had 600-2000 detections per day. At typical burst durations, this adds up to about 6 min of stimulation per day.

A multi-center RCT demonstrated the safety and effectiveness of RNS. Over 3 months of the blinded period, the overall reduction in disabling seizure frequency in the treated patients (38\%) was significantly larger than in the sham patients (17\%) (Morrell and Group RNSSiES 2011). Seizure frequency reductions begin with initiation of treatment and continue over time, reaching median reductions of $75 \%$ after 9 years of treatment. Treatment with responsive cortical stimulation is also associated with an improvement in quality of life and cognitive function related to the functional area being treated.

\section{Chronic subthreshold cortical stimulation (CSCS)}

CSCS is an open-loop subthreshold stimulation via subdural electrodes that targets the $\mathrm{SOZ}$ (Kerezoudis et al. 2018; Lundstrom et al. 2019; Starnes et al. 2019). Potential candidates are identified while undergoing intracranial EEG monitoring. Seizure frequency as well as the frequency of interictal epileptiform discharges are used to assess the potential efficacy of multiple stimulation paradigms. First clinical data indicate positive effects on focal seizure frequency and severity (Kerezoudis et al. 2018; Starnes et al. 2019).

A recent retrospective analysis addressed potential interictal EEG biomarkers recorded during trial stimulation that may predict anticonvulsant efficacy of permanent CSCS (Lundstrom et al. 2019). When intracranial EEG monitoring advised against potential surgical resection of the SOZ, patients were offered a 1 to 4 days therapeutic trial of continuous electrical stimulation (biphasic; frequency $2-100 \mathrm{~Hz}$; pulse width 90-450 $\mu$ s; amplitude $1-6 \mathrm{~V}$ ) targeting the $\mathrm{SOZ}$ and surrounding tissue using the already implanted temporary electrodes applied for invasive monitoring. The primary purpose of the trial stimulation was to optimize stimulation location and stimulation parameters via individual assessment of EEG epileptiform activity in response to stimulation. In the vast majority of 21 patients a stimulation frequency of about $2 \mathrm{~Hz}$ during invasive monitoring effectively reduced interictal epileptiform discharges and seizure activity. Permanent stimulation hardware was implanted when intracranial EEG electrodes were explanted. Three months after stimulation initiation, the responder rate with at least $50 \%$ seizure reduction was $79 \%$, the median reduction in seizure frequency was $93 \%$. With a median follow-up of 27 months, in the most recent 3 months period the responder rate was $89 \%$ with a median reduction in seizure frequency of $100 \%$. About $40 \%$ of patients were free of disabling seizures for a 12 months period or longer. It was demonstrated that stimulation induced decreases in delta $(1-4 \mathrm{~Hz})$ power and increases in alpha and beta $(8-20 \mathrm{~Hz})$ power during trial stimulation correlated with improved long-term clinical outcomes. CSCS has been implemented via off-label usage of FDAapproved hardware. The authors suggested that CSCS may be an effective alternative approach in the treatment of pharmacoresistant focal epilepsies and that shortterm stimulation-related changes in EEG spectral power may be a useful interictal biomarker that seems to relate to long-term clinical outcome (Lundstrom et al. 2019).

\section{Epicranial cortical stimulation (ECS)}

Epicranial application of electrical stimulation may combine minimal invasiveness with sustained efficacy of neuromodulation in focal epilepsies. Preclinical experiments in rodents applied epicranially implanted electrodes in order to selectively stimulate the motor cortex. Experiments demonstrated focused limb movements by ECS with a design of concentric ring electrodes according to Laplace (Khatoun et al. 2019). The combination of a minimally invasive epicranial electrode and an internal pulse generator recently made the first move into clinical development (Schulze-Bonhage 2019). The epicranial array consists of five electrodes arranged in a pseudoLaplacian geometry, with a central electrode surrounded by four peripheral electrodes allowing precise individual targeting of defined neocortical brain areas (Alam et al. 2016; Saturnino et al. 2015). Electrical field simulation via finite element method based on a high-resolution head model indicates substantial field strength as compared to noninvasive neurostimulation (Fig. 1) (Saturnino et al. 2015). In contrast to other invasive devices, the electrode is not placed intracranially but in the subgaleal space between the scalp and skull. Based upon clinical outcomes of noninvasive cathodal tDCS and intracranial RNS in focal epilepsies, ECS combines two stimulation paradigms in ongoing clinical trials (EASEEII n.d.; PIMIDES-I n.d). Asymmetric, rectangular pulses with durations of $20 \mathrm{~ms}$ and $100 \mathrm{~ms}$ of cathodal and anodal half-waves, respectively, are applied with a frequency of $8 \mathrm{~Hz}$ for $20 \mathrm{~min}$ a day resembling tDCS. AC bursts of $500 \mathrm{~ms}$ duration consist of biphasic, rectangular pulses $(320 \mu \mathrm{s}, 100 \mathrm{~Hz})$ and are applied every $2 \mathrm{mi}-$ nutes throughout the day; Daily duration of AC bursts adds up to 6 min which is similar to RNS. Both stimulation paradigms are individually adjusted to subthreshold stimulus intensities below $4 \mathrm{~mA}$. Besides the open-loop subthreshold stimulation that is delivered at regular intervals throughout the day in the evaluation period of the clinical trials, the PIMIDES-I study offers additional 

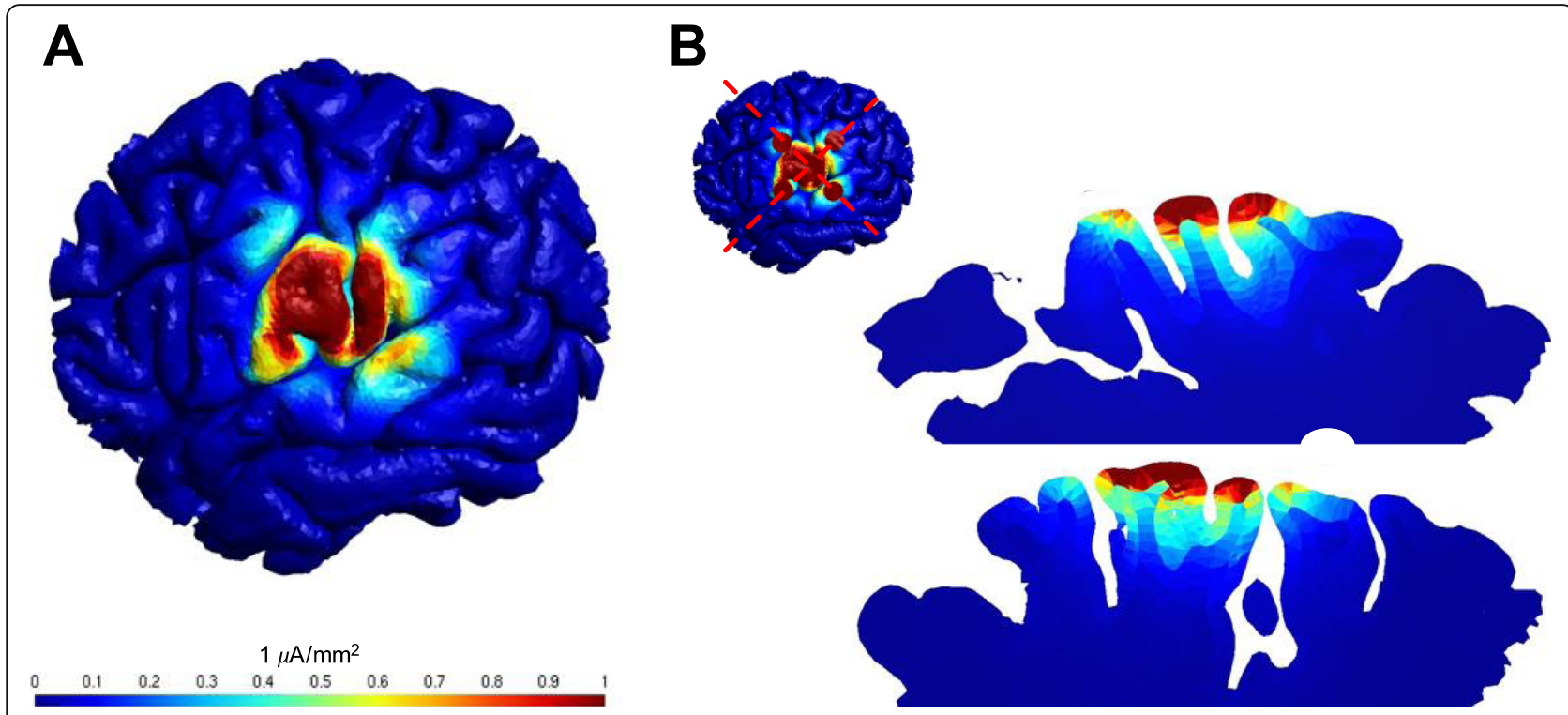

Fig. 1 Electrical field simulation via finite element method based on a high-resolution head model. Electrical stimulation of the left parietotemporal cortex is applied by an epicranial array consisting of five electrodes arranged in a pseudo-Laplacian geometry, with a central electrode surrounded by four peripheral electrodes. a Top view of the current density distribution. b Cross sections in two perpendicular layers with intracortical current density distribution

bolus stimulation in order to provide patients the ability to manually deliver an additional dose of therapy in an effort to stop or shorten a seizure once it starts (PIMI DES-I n.d.). Both clinical trials include more than 30 patients suffering from pharmacoresistant focal epilepsies and are ongoing, first results are expected in 2021.

\section{Mode of action}

\section{Seizure termination}

Direct electrical stimulation has been applied to the cortex for mapping purposes for about 90 years (Luders et al. 1988). Cortical localization stimuli may provoke epileptiform afterdischarges, and these can evolve into clinical seizure. These afterdischarges are a preliminary stage of seizures and, therefore, used as a model of epileptiform activity. High-frequency cortical stimulation of $50 \mathrm{~Hz}$ was performed for clinical localization purposes using subdural electrodes implanted in patients undergoing preresection evaluations for treatment of pharmacoresistant seizures (Lesser et al. 1999). When high-frequency stimulation produced afterdischarges, brief bursts of additional stimulation were applied in order to prove its effectiveness in aborting afterdischarges in 17 epilepsy patients. Afterdischarges significantly decreased in duration after the application of brief bursts. These results support the idea that high-frequency electrical stimulation, applied in an appropriate manner at seizure onset, could abort seizures in humans. Further studies in epilepsy patients have also reported on shortening or termination of epileptiform discharges by high-frequency electrical cortical stimulation (Chkhenkeli et al. 2004; Motamedi et al. 2002). RNS mainly is based upon the termination of epileptiform brain activity by high-frequency cortical stimulation (Morrell 2006).

Obviously, high-frequency electrical stimulation is able to provoke opponent effects in the brain, it might induce epileptiform activity but may also terminate those discharges and subsequently initiating seizures as well (Lesser et al. 1999). Mechanisms of synaptic plasticity delineated by the model of long-term potentiation (LTP) are similar to those underlying epileptogenesis by kindling (Meador 2007; Weiss et al. 1995). Both kindling and LTP are most effectively induced by high-frequency stimulation and share overlapping molecular mechanisms.

\section{Long-term depression (LTD)}

Kindling is the progressive development of seizures to a previously subconvulsant stimulus (Goddard et al. 1969). Rats were kindled by daily application of high-frequency electrical stimulation to the amygdala (Weiss et al. 1995). Kindling was characterized by decreased thresholds and increased durations of afterdischarges and seizures. Additional low-frequency stimulation (LFS; 1 $\mathrm{Hz}, 15 \mathrm{~min}$ ) blocked the development and progression of afterdischarges and seizures in seven out of eight animals. In fully kindled animals once daily LFS for 1 week suppressed seizures when the kindling stimulation was resumed. It is suggested that LFS effectuates long-lasting anticonvulsant effects mediated by LTD (Weiss et al. 1995).

Although LTD has been investigated intensively in animal models (Braunewell and Manahan-Vaughan 2001; Ellrich 2004; Kemp and Bashir 2001), only few studies 
have focused on possible mechanisms involved in this synaptic plasticity model in humans. Electrical LFS induced LTD of brainstem reflexes (Ellrich and Schorr 2002; Schorr and Ellrich 2002) and somatosensory brain processing assessed by electrophysiological (Ellrich and Schorr 2004; Jung et al. 2009; Rottmann et al. 2008), psychophysical (Rottmann et al. 2010a), and imaging methods (Rottmann et al. 2010b) in humans.

The common denominator in the vast majority of LTD studies is the application of LFS in the range of 0.5 to $3 \mathrm{~Hz}$. This applies to noninvasive TMS with main frequencies of repetitive stimulation between 0.5 and $1 \mathrm{~Hz}$ (Lefaucheur et al. 2020; Mishra et al. 2020) and intracranial CSCS with $2 \mathrm{~Hz}$ LFS (Lundstrom et al. 2019) in patients with focal epilepsies.

LFS induces LTD by N-Methyl-D-aspartate (NMDA) receptor activation and the subsequent slight increase in $\mathrm{Ca}^{2+}$ activating calcineurin which stimulates protein phosphatase 1 (PP1) (Xia and Storm 2005). Activation of PP1 catalyzes the dephosphorylation of several proteins.

Noninvasive cathodal tDCS is suggested to provoke transient and long-term effects on cortical excitability (Antal et al. 2017; Luu et al. 2016; Nitsche et al. 2003; Nitsche and Paulus 2000; Stagg et al. 2018) and epileptiform discharges (Holmes et al. 2019; VanHaerents et al. 2020; Yang et al. 2020). Whereas acute effects of cathodal tDCS are due to transient hyperpolarization of cortical neurons (Nitsche et al. 2003; Nitsche and Paulus 2000), human experimental studies provide evidence that long-term effects base upon LTD (Stagg et al. 2018). Pharmacological studies show that a blockade of NMDA receptors prevents sustained tDCS-induced inhibition in human and experimental studies (Chang et al. 2015; Nitsche et al. 2003). Blockade of PP1 by okadaic acid in the same experimental model suspended long-term inhibition of cathodal tDCS and spared acute effects (Chang et al. 2015). Low-frequency magnetic or electrical stimulation and cathodal tDCS seem to share LTD as a common mode of action. Depending on experimental model and stimulation parameters, LTD effects may last hours to weeks. Sustainability of LTD may define noninvasive and invasive stimulation paradigms.

\section{Conclusions}

Electrical or magnetic stimulations of cortical brain areas for the treatment of pharmacoresistant focal epilepsies emerged from preclinical studies and experience from intraoperative neurophysiological monitoring in patients (Table 1). Noninvasive low-frequency TMS and cathodal tDCS are suggested to be anticonvulsant, however, potential effects are ephemeral and may require effect maintenance by ongoing stimulation. Invasive RNS, CSCS, and ECS cover a broad range of different emerging technologies with intracranial and epicranial approaches that still have limited market access partly due to ongoing clinical development. Despite significant differences, the present bioelectronic technologies share common mode of actions with acute seizure termination by high-frequency stimulation and LTD induced by lowfrequency magnetic or electrical stimulation or tDCS. Focused cortical stimulation with synergistic mode of actions seems to be a promising option for sustained anticonvulsant treatment of one third of epilepsy patients that suffer from ongoing seizures and adverse effects of drug treatment.

\section{Abbreviations \\ ACD: Anticonvulsant Drug; CSCS: Chronic Subthreshold Cortical Stimulation; DBS: Deep Brain Stimulation; ECS: Epicranial Cortical Stimulation; \\ EEG: ElectroEncephaloGraphy; LFS: Low-Frequency Stimulation; LTD: Long- Term Depression; LTP: Long-Term Potentiation; NMDA: N-Methyl-D-Aspartate; PP1: Protein Phosphatase 1; RCT: Randomized Controlled Trial; RNS: Responsive NeuroStimulation; SOZ: Seizure Onset Zone; tDCS: transcranial Direct Current Stimulation; TEAE: Treatment-Emergent Adverse Event; TMS: Transcranial Magnetic Stimulation; VNS: Vagus Nerve Stimulation}

\section{Acknowledgements}

The author thanks Rebecca Ellrich, B.A., B.S. (Elon University, NC, USA) for proofreading.

\section{Author's contributions}

J.E. is the sole author of the manuscript. The author read and approved the final manuscript.

\section{Funding}

Open access funding provided by Projekt DEAL.

Availability of data and materials

Not applicable.

Ethics approval and consent to participate

Not applicable.

Consent for publication

Not applicable.

Competing interests

J.E. is Chief Medical Officer of Precisis AG.

Received: 23 July 2020 Accepted: 25 August 2020

Published online: 25 September 2020

\section{References}

Alam M, Truong DQ, Khadka N, Bikson M. Spatial and polarity precision of concentric high-definition transcranial direct current stimulation (HD-tDCS). Phys Med Biol. 2016;61(12):4506-21.

Antal A, Alekseichuk I, Bikson M, Brockmoller J, Brunoni AR, Chen R, et al. Low intensity transcranial electric stimulation: safety, ethical, legal regulatory and application guidelines. Clin Neurophysiol. 2017;128(9):1774-809.

Baulac M, Brodie MJ, Patten A, Segieth J, Giorgi L. Efficacy and tolerability of zonisamide versus controlled-release carbamazepine for newly diagnosed partial epilepsy: a phase 3, randomised, double-blind, non-inferiority trial. Lancet Neurol. 2012;11(7):579-88.

Baulac M, Rosenow F, Toledo M, Terada K, Li T, De Backer M, et al. Efficacy, safety, and tolerability of lacosamide monotherapy versus controlled-release carbamazepine in patients with newly diagnosed epilepsy: a phase 3 , randomised, double-blind, non-inferiority trial. Lancet Neurol. 2017;16(1):43-54

Beghi E. The epidemiology of epilepsy. Neuroepidemiology. 2020;54(2):185-91.

Billakota S, Devinsky O, Kim KW. Why we urgently need improved epilepsy therapies for adult patients. Neuropharmacology. 2020;170:107855. 
Braunewell KH, Manahan-Vaughan D. Long-term depression: a cellular basis for learning? Rev Neurosci. 2001;12(2):121-40.

Brodie MJ, Perucca E, Ryvlin P, Ben-Menachem E, Meencke HJ, Levetiracetam Monotherapy Study G. Comparison of levetiracetam and controlled-release carbamazepine in newly diagnosed epilepsy. Neurology. 2007;68(6):402-8.

Chang WP, Lu HC, Shyu BC. Treatment with direct-current stimulation against cingulate seizure-like activity induced by 4-aminopyridine and bicuculline in an in vitro mouse model. Exp Neurol. 2015;265:180-92.

Chen Z, Brodie MJ, Kwan P. What has been the impact of new drug treatments on epilepsy? Curr Opin Neurol. 2020;33(2):185-90.

Chkhenkeli SA, Sramka M, Lortkipanidze GS, Rakviashvili TN, Bregvadze E, Magalashvili GE, et al. Electrophysiological effects and clinical results of direct brain stimulation for intractable epilepsy. Clin Neurol Neurosurg. 2004;106(4): 318-29.

EASEE-II. Available from: https://apps.who.int/trialsearch/Trial2.aspx? TrialID= DRKS00015918. [Accessed 16 July 2020].

Ellrich J. Electric low-frequency stimulation of the tongue induces long-term depression of the jaw-opening reflex in anesthetized mice. J Neurophysiol. 2004;92(6):3332-7.

Ellrich J, Schorr A. Long-term depression of the human masseter inhibitory reflex. Neurosci Lett. 2002;329(3):265-8.

Ellrich J, Schorr A. Low-frequency stimulation of trigeminal afferents induces long-term depression of human sensory processing. Brain Res. 2004;996(2): 255-8.

Engel J Jr. The current place of epilepsy surgery. Curr Opin Neurol. 2018;31(2): 192-7.

FDA. Summary of safety and effectiveness data; 2013. Available from: https://www. accessdata.fda.gov/cdrh_docs/pdf10/P100026B.pdf. [Accessed 17 Aug 2020].

Forsgren L, Bucht G, Eriksson S, Bergmark L. Incidence and clinical characterization of unprovoked seizures in adults: a prospective populationbased study. Epilepsia. 1996;37(3):224-9.

Fregni F, Otachi PT, Do Valle A, Boggio PS, Thut G, Rigonatti SP, et al. A randomized clinical trial of repetitive transcranial magnetic stimulation in patients with refractory epilepsy. Ann Neurol. 2006;60(4):447-55.

Goddard GV, McIntyre DC, Leech CK. A permanent change in brain function resulting from daily electrical stimulation. Exp Neurol. 1969;25(3):295-330.

Gonzalez HFJ, Yengo-Kahn A, Englot DJ. Vagus nerve stimulation for the treatment of epilepsy. Neurosurg Clin N Am. 2019;30(2):219-30.

Hamer HML, J. D, Richter S, Watermann N, Strzelczyk A. Gesundheitsökonomie und Lebensqualität bei Epilepsie. Z Epileptol. 2015;28:153-60.

Heck CN, King-Stephens D, Massey AD, Nair DR, Jobst BC, Barkley GL, et al. Twoyear seizure reduction in adults with medically intractable partial onset epilepsy treated with responsive neurostimulation: final results of the RNS system pivotal trial. Epilepsia. 2014;55(3):432-41.

Holmes MD, Feng R, Wise MV, Ma C, Ramon C, Wu J, et al. Safety of slow-pulsed transcranial electrical stimulation in acute spike suppression. Ann Clin Transl Neurol. 2019;6(12):2579-85.

Janmohamed M, Brodie MJ, Kwan P. Pharmacoresistance - epidemiology, mechanisms, and impact on epilepsy treatment. Neuropharmacology. 2020; 168:107790.

Jung K, Rottmann S, Ellrich J. Long-term depression of spinal nociception and pain in man: influence of varying stimulation parameters. Eur J Pain. 2009; 13(2):161-70.

Kemp N, Bashir Zl. Long-term depression: a cascade of induction and expression mechanisms. Prog Neurobiol. 2001;65(4):339-65.

Kerezoudis P, Grewal SS, Stead M, Lundstrom BN, Britton JW, Shin C, et al. Chronic subthreshold cortical stimulation for adult drug-resistant focal epilepsy: safety, feasibility, and technique. J Neurosurg. 2018;129(2):53343.

Khatoun A, Asamoah B, Mc LM. Investigating the feasibility of Epicranial cortical stimulation using concentric-ring electrodes: a novel minimally invasive neuromodulation method. Front Neurosci. 2019;13:773.

Kwan P, Arzimanoglou A, Berg AT, Brodie MJ, Allen Hauser W, Mathern G, et al. Definition of drug resistant epilepsy: consensus proposal by the ad hoc task force of the ILAE commission on therapeutic strategies. Epilepsia. 2010;51(6): 1069-77.

Lattanzi S, Zaccara G, Giovannelli F, Grillo E, Nardone R, Silvestrini M, et al. Antiepileptic monotherapy in newly diagnosed focal epilepsy. A network meta-analysis. Acta Neurol Scand. 2019;139(1):33-41.

Lefaucheur JP, Aleman A, Baeken C, Benninger DH, Brunelin J, Di Lazzaro V, et al. Evidence-based guidelines on the therapeutic use of repetitive transcranial magnetic stimulation (rTMS): an update (2014-2018). Clin Neurophysiol. 2020; 131(2):474-528.

Lefaucheur JP, Antal A, Ayache SS, Benninger DH, Brunelin J, Cogiamanian F, et al. Evidence-based guidelines on the therapeutic use of transcranial direct current stimulation (tDCS). Clin Neurophysiol. 2017;128(1):56-92.

Lesser RP, Kim SH, Beyderman L, Miglioretti DL, Webber WR, Bare M, et al. Brief bursts of pulse stimulation terminate afterdischarges caused by cortical stimulation. Neurology. 1999;53(9):2073-81.

Loscher W, Schmidt D. Epilepsy: perampanel-new promise for refractory epilepsy? Nat Rev Neurol. 2012;8(12):661-2.

Luders H, Lesser RP, Dinner DS, Morris HH, Wyllie E, Godoy J. Localization of cortical function: new information from extraoperative monitoring of patients with epilepsy. Epilepsia. 1988;29(Suppl 2):S56-65.

Lundstrom BN, Gompel JV, Khadjevand F, Worrell G, Stead M. Chronic subthreshold cortical stimulation and stimulation-related EEG biomarkers for focal epilepsy. Brain Commun. 2019;1(1):fcz010.

Luoni C, Bisulli F, Canevini MP, De Sarro G, Fattore C, Galimberti CA, et al. Determinants of health-related quality of life in pharmacoresistant epilepsy: results from a large multicenter study of consecutively enrolled patients using validated quantitative assessments. Epilepsia. 2011;52(12):2181-91.

Luu P, Essaki Arumugam EM, Anderson E, Gunn A, Rech D, Turovets S, et al. Slow-frequency pulsed transcranial electrical stimulation for modulation of cortical plasticity based on reciprocity targeting with precision electrical head modeling. Front Hum Neurosci. 2016;10:377.

Malek N, Heath CA, Greene J. A review of medication adherence in people with epilepsy. Acta Neurol Scand. 2017;135(5):507-15.

Meador KJ. The basic science of memory as it applies to epilepsy. Epilepsia. 2007; 48(Suppl 9):23-5.

Mishra A, Maiti R, Mishra BR, Jena M, Srinivasan A. Effect of repetitive transcranial magnetic stimulation on seizure frequency and epileptiform discharges in drug-resistant epilepsy: a meta-analysis. J Clin Neurol. 2020;16(1):9-18.

Morrell M. Brain stimulation for epilepsy: can scheduled or responsive neurostimulation stop seizures? Curr Opin Neurol. 2006;19(2):164-8.

Morrell MJ, Group RNSSiES. Responsive cortical stimulation for the treatment of medically intractable partial epilepsy. Neurology. 2011;77(13):1295-304.

Motamedi GK, Lesser RP, Miglioretti DL, Mizuno-Matsumoto Y, Gordon B, Webber WR, et al. Optimizing parameters for terminating cortical afterdischarges with pulse stimulation. Epilepsia. 2002;43(8):836-46.

Nair DR, Laxer KD, Weber PB, Murro AM, Park YD, Barkley GL, et al. Nine-year prospective efficacy and safety of brain-responsive neurostimulation for focal epilepsy. Neurology. 2020; in press. https://doi.org/10.1212/WNL. 0000000000010154

Ngugi AK, Bottomley C, Kleinschmidt I, Sander JW, Newton CR. Estimation of the burden of active and life-time epilepsy: a meta-analytic approach. Epilepsia. 2010:51(5):883-90.

Nitsche MA, Fricke K, Henschke U, Schlitterlau A, Liebetanz D, Lang N, et al. Pharmacological modulation of cortical excitability shifts induced by transcranial direct current stimulation in humans. J Physiol. 2003;553(Pt 1):293-301.

Nitsche MA, Paulus W. Excitability changes induced in the human motor cortex by weak transcranial direct current stimulation. J Physiol. 2000;527(Pt 3):633-9.

Penfield W, Jasper $\mathrm{H}$. Epilepsy and the functional anatomy of the human brain. Boston: Little Brown; 1954.

PIMIDES-I. Available from: https://apps.who.int/trialsearch/Trial2.aspx? TriallD= DRKS00017833. [Accessed 16 July 2020].

Rottmann S, Jung K, Ellrich J. Electrical low-frequency stimulation induces homotopic long-term depression of nociception and pain from hand in man. Clin Neurophysiol. 2008;119(8):1895-904.

Rottmann S, Jung K, Ellrich J. Electrical low-frequency stimulation induces longterm depression of sensory and affective components of pain in healthy man. Eur J Pain. 2010a;14(4):359-65.

Rottmann S, Jung K, Vohn R, Ellrich J. Long-term depression of pain-related cerebral activation in healthy man: an fMRI study. Eur J Pain. 2010b;14(6): 615-24.

Salanova V, Witt T, Worth R, Henry TR, Gross RE, Nazzaro JM, et al. Long-term efficacy and safety of thalamic stimulation for drug-resistant partial epilepsy. Neurology. 2015;84(10):1017-25.

Saturnino GB, Antunes A, Thielscher A. On the importance of electrode parameters for shaping electric field patterns generated by tDCS. Neuroimage. 2015;120:25-35.

Schorr A, Ellrich J. Long-term depression of the human blink reflex. Exp Brain Res. 2002;147(4):549-53. 
Schulze-Bonhage A. Epikraniale stimulation in Prüfung. Dtsch Arztebl. 2019;116: 26-30.

Skarpaas TL, Jarosiewicz B, Morrell MJ. Brain-responsive neurostimulation for epilepsy (RNS((R)) system). Epilepsy Res. 2019;153:68-70.

Stagg CI, Antal A, Nitsche MA. Physiology of transcranial direct current stimulation. J ECT. 2018;34(3):144-52.

Starnes K, Miller K, Wong-Kisiel L, Lundstrom BN. A review of Neurostimulation for epilepsy in pediatrics. Brain Sci. 2019;9(10):283.

Sun W, Mao W, Meng X, Wang D, Qiao L, Tao W, et al. Low-frequency repetitive transcranial magnetic stimulation for the treatment of refractory partial epilepsy: a controlled clinical study. Epilepsia. 2012;53(10):1782-9.

Tang F, Hartz AMS, Bauer B. Drug-resistant epilepsy: multiple hypotheses, few answers. Front Neurol. 2017;8:301.

Trinka E, Ben-Menachem E, Kowacs PA, Elger C, Keller B, Loffler K, et al. Efficacy and safety of eslicarbazepine acetate versus controlled-release carbamazepine monotherapy in newly diagnosed epilepsy: a phase III double-blind, randomized, parallel-group, multicenter study. Epilepsia. 2018; 59(2):479-91.

VanHaerents S, Chang BS, Rotenberg A, Pascual-Leone A, Shafi MM. Noninvasive brain stimulation in epilepsy. J Clin Neurophysiol. 2020;37(2):118-30.

Weiss SR, Li XL, Rosen JB, Li H, Heynen T, Post RM. Quenching: inhibition of development and expression of amygdala kindled seizures with low frequency stimulation. Neuroreport. 1995;6(16):2171-6.

Xia Z, Storm DR. The role of calmodulin as a signal integrator for synaptic plasticity. Nat Rev Neurosci. 2005;6(4):267-76.

Yang D, Wang Q, Xu C, Fang F, Fan J, Li L, et al. Transcranial direct current stimulation reduces seizure frequency in patients with refractory focal epilepsy: a randomized, double-blind, sham-controlled, and three-arm parallel multicenter study. Brain Stimul. 2020;13(1):109-16.

\section{Publisher's Note}

Springer Nature remains neutral with regard to jurisdictional claims in published maps and institutional affiliations.

Ready to submit your research? Choose BMC and benefit from:

- fast, convenient online submission

- thorough peer review by experienced researchers in your field

- rapid publication on acceptance

- support for research data, including large and complex data types

- gold Open Access which fosters wider collaboration and increased citations

- maximum visibility for your research: over $100 \mathrm{M}$ website views per year

At $\mathrm{BMC}$, research is always in progress.

Learn more biomedcentral.com/submissions 